\title{
Artificial Intelligence, Soft Power and Social Transformation
}

\author{
Naren Chitty ${ }^{1} \&$ Sabina Dias 2
}

\begin{abstract}
Convergent technologies have created new venues for virtual social interaction and influence, both hard and soft power based. These new theatres of culture and conflict and marketplaces for constructs and products also host virtual agents of organizations and individuals.

Technological convergence takes place within the current uneven global societal convergence and evolution of rules and rule that emerge through the interplay of propensities for hierarchy, hegemony and heteronomy, propensities identified in Onuf's constructivism. An overarching social construction that maybe characterized as a weak world confederacy (WC) with republican characteristics has emerged.

Human and machine intelligence and kinetics continue to converge within and with the WC, which may be characterized as a growing 'cyber organization' - or system composed of human and social subsystems as well as subsystems of human constructs - ideological and technological.

Looking into the future techno-social transformation may be projected to range between (1) a point where human mind (in its collective social expression as WC) is at the apex of the power hierarchy and (2) another where technology (in the form of a much-progressed technological singularity, no longer supported by human intelligence external to it) is at the apex. In between would be a range of Whole Brain Emulations (Ems) as described in Robin Hanson's The Age of Em: Work, Love and Life when Robots Rule the Earth.

This article will discuss power and techno-biological convergence and employ a constructivist approach to analyze social order as projected in The Age of Em. It will also raise political-economic questions in the leadup to singularity, when Van Neumann machines will be available. It will normatively take the view that the republican values and virtues of the current world system should prevail in the shaping of any evolving WBE regime. It will call for the transfer of norms to ems and artilects as far into the future as possible. In the time ahead, the question of how human society might balance power with a power-oriented artilect might be our principal concern. Might this happen through interplay of hierarchy, hegemony and heteronomy continuing through phases of global cyber organization?
\end{abstract}

Keywords: Artificial Intelligence, homonomy, humanism, international regimes, normatavization, soft power, systems

\section{Introduction}

The linking, for discussion, of the terms technology, power and social transformation, offers a canvas as expansive as human experience itself. Technological advantage affords individuals and organizations power over others to shape social transformation, through communication of content-and hopefully to attain contentment. Technology can itself shape social transformation. The position taken here is that ideology, defined here as systematized ideas that, if followed in a prescribed manner, will lead to a preferred social outcome. Ideology - "a system of ideas and ideals" (English Oxford Living Dictionaries) is viewed here as a soft technology; technology - "a manner of accomplishing a task" (Merriam-Webster Dictionary) is task-oriented ideology, often though not always with material

\footnotetext{
1 Chair in International Communication Macquarie University

2 Australian lawyer
}

expression. Thus, power, technology, and ideology and their relation to social transformation or ameliorative social change, are all important here.

Late twentieth century technological convergence started with the melding of informatics and telecommunications through shared electronics. Bionic convergence took this further towards the promise or peril of Artificial Intelligence (AI or artilects) ${ }^{1}$. By the second decade of the $21^{\text {st }}$ Century the proliferation of networks and an expanding universe of peripherals had resulted in the Internet of Things (IoT, a network of peripherals) ${ }^{2}$ and the Internet of Everything (IoE -

1 Artilect is a term coined by Hugo de Garis (de Garis, 2005).

2 "Simply put, this is the concept of basically connecting any device with an on and off switch to the Internet (and/or to each other). This includes everything from cellphones, 
or "the intelligent connection of people, process, data and things") (CISCO). Critics would say that this also gifts further affordance, to AI and provides a nest for its development. Deep learning technologies for computers would provide sustenance for an evolving IoE. Autopoietic Van Neuman machines 3 and convergent artilects have the potential of dominating IoT and through it the IoE with its human interface - in an all-powerful 'artilecture'. Artilecture can both be the artilect-social system and its manifestations as well as the discourse on artilects and society (communication of content). Another aspect of bionic transformation would be Whole Brain Emulations, a topic discussed in Age of Em: Work, Love and Life when Robots Rule the Earth (Hanson 2016).

Conceptions of relationships between AI and society are examined here from the perspective of constructivism in world politics. Constructivism will be introduced first along with Onuf's three rules of functional grounds for world politics: Hegemony, hierarchy and heteronomy (Onuf 2014). The notion of homonomy will also be discussed in relation to systems theory and power - soft and hard (Chitty 2017a). Humanism and human security orientation, a character of republicanism, in the current world polity that is characterized by Chitty (2017a) as a weak world confederacy, is discussed along with the role of normatavization in furthering republican values. It is within this comity that the next cyber organizational plateau of social transformation is being shaped by the IoE. Following this there will be a discussion of AI scenarios; then a normative discussion of future world politics and cyber organization; an examination of some initiatives regarding $\mathrm{AI}$ regulation and legislation with special attention to the European Union;and a conclusion.

\section{Heteronomy, autonomy, homonomy and cyber organization}

Constructivists resolved the contradictions between neoliberal and neorealist schools, in their own minds, by positing world politics to be a construction of mind (Wendt 1999). Their

coffee makers, washing machines, headphones, lamps, wearable devices and almost anything else you can think of. This also applies to components of machines, for example a jet engine of an airplane or the drill of an oil rig" (Morgan, 2016).

3 Self-replicating machines named after the physicist/computer scientist John Von Neumann. construction, dubbed 'constructivism', "formed the synthesis which allowed societies to construct world politics in realist, liberal or other images through words and deeds" (Chitty 2017a). World politics was not shaped by competitive valuemaximizing (neorealist) or cooperative (neoliberal) human nature but rather by social interaction (constructivism) that could posit inter alia realism/neo-realism, liberalism/neoliberalism and constructivism. Unlike the other two schools that are positivist, constructivism has been characterized as being post positivist (Chitty 2017a). Onuf, a hard constructivist, discerns three underlying types of rule (hegemony, hierarchy and heteronomy) that one might argue are products of competitive and cooperative behavior; these are associated with types of rules (instruction, directives and reciprocal limitations). Instruction rules establish hegemony, directive-rules establish hierarchy. A "reciprocal set of limitations on our individual autonomy yields heteronomy" (Onuf 1997). The great conundrum for man in society is how to retain desired levels of autonomy while accepting beneficial heteronomy. When heteronomy is disfavored or resisted, it is likely because it is experienced as unpalatably extensive, invasive and coercive in varying degrees.

Conversely, when a suitable balance of reciprocal constraints results in a happy acceptance of the relationship, in a mature stoicism, where the will of the individual and the larger entity do not clash, there is a condition of homonomy experienced by the individual.Epictetus (Dobbin 2008); (Epictetus 1925) believed that people were interconnected parts of a whole that needed to be viewed as a harmony; the individual needed to be tolerant of vicissitudes and essentially be happy with his own lot. To be content with one's own lot is easier if one's lot is presented in terms of an attractive ideology - even as stoicism. Where there is an attractive variable, such as an ideology invested in soft power between an actor exercising heteronomy over another and the other, homonomy becomes possible as something generated in his or her own mind by the actor over whom heteronomy is exercised. "Homonomy and heteronomy are constantly at odds here in tussles between entropic and disentropic normativeforces" (Chitty 2017a). Homonomy- a situational contentment can befacilitated by soft power relations or interactions of attraction overlaying any heteronomic relationship through attractive ideology presented in content, but the generation of homonomy will still be in the mind of the individual. An ideology deemed attractive may 
be dismissed by an individual, so while rhetoric may deliver, there is a psychological dimension for an individual's acceptance. In his psychological theory Angyal's antonyms, homonomy and autonomy, refer to selfsurrender, as opposed to autonomy or selfdetermination, of the organism with respect to the larger biosphere (Angyal 1969) or the system that connects our physical and biological environments with ourselves. "However, homonomy is not simply the relation of part-topart and nor part-to-whole; it is the relation of part-to-part within the whole" (Emery 1977). Emery argues that the pursuit of Beauty "entices an ideal seeking system to enlarge its desires and to find its succeeding intentions of even greater value". Humanity has progressively constructed an international system, one that seeks to achieve its ideals by incrementally improving human conditions through the espousal of humanist law and policy.

Systems theory drew on biological insights to explain complex relationships in the social realm. A 'whole' consisting of interrelated parts or subsystems is identified as a system. For a system to work optimally its subsystems need to support it by fulfilling functions. A system operates in an environment, has boundaries that define it vis-àvis the environment and may receive inputs from the environment and release outputs to it. It needs to expend energy to overcome the natural tide of entropy and retain its structure and vitality.

Intelligent systems are hierarchically related substructures that support the objectives of a composite structure, unified by objectives that operate in an environment. Inany simpleintelligent system there is a coordinating substructure that receives information from within and without the system and makes decisions and issuesdirectives that shape responses (Easton 1965; von Bertalanffy, 1972). It is at the apex of a hierarchy of subsystems.In complex social systems hierarchies are not quite so absolute. This becomes evident when one compares a well-operating national system and the world system. The contemporary world order has been described as a weak world confederacy (republican in nature) rather than a federation, recognizing the collective rule-making that constructs a system of rule despite there being no single unified state (Chitty2017a). There are ebbs and flows to the growth of the confederacy; itstransformation is not necessarily a historically and collectively unidirectional process - but all states and cultures are contained within the same, now interconnected, planetary environment that ensures bouts of cooperation and conflict. Conflicts can be not only about resources but also about the way resources are viewed and about forms of government.

One might argue with the notion that in advanced life forms:“[u]nlike countries...nervous systems can implement multiple forms of government simultaneously. A neuronal dictatorship can coexist with an oligarchy or democracy. The dictator, acting fastest, may trigger the onset of a behavior while other neurons fine-tune the ensuing movements. There does not need to be a single form of government as long as the behavioral consequences increase the probability of survival and reproduction" (Berkowitz 2016). However, one does see protocols for different levels of response particularly in countries and groups of countries, such as federations (Australia, India, US) and confederations (European Community) with more decentralized systems, and even in more centralized systems such as China - whatever might be the overall form of government. It may further be said that " $[\mathrm{t}]$ technologically supported social networks link the centers of power and contribute to a measure of homonomy, in flux, in the confederacy, while enhancing effects of countervailing normative impulses that are part and parcel of heteronomy", bearing in mind that regardless of the rhetoric in social networks, homonomy is a construction of the individual mind in its systemic setting (Chitty 2017a). Content and communication to which he is exposed Heteronomy arranges society in hierarchical layers regardless of whether there is a positive stoic acceptance of each of us as being citizens of our own states as well as belonging to a larger system. Homonomy is where there is a happy acceptance of or contentment with interrelationships. Hierarchy, hegemony and heteronomy, world political propensities identified in Onuf's constructivism, are all associated with dominance and may elicit desires variously for autonomy (Onuf 2014). Hegemony may be a dominance imposed by ideas, norms and culture and supported by capacities for coercion or inducement (hard power). But the ideas, norms and culture when attractive (soft power) could continue to be supported by capacities for coercion or inducement (hard power) that in themselves may be attractive to some and not to others. There is the possible response of a positive self-surrender, based on the right balance of reciprocal constraints resulting in a happy acceptance of the relationship, in homonomy. These relationships are depicted in 
Table 1.

Table 1 Intended influence, hegemony, heteronomy, homonomy and autonomy

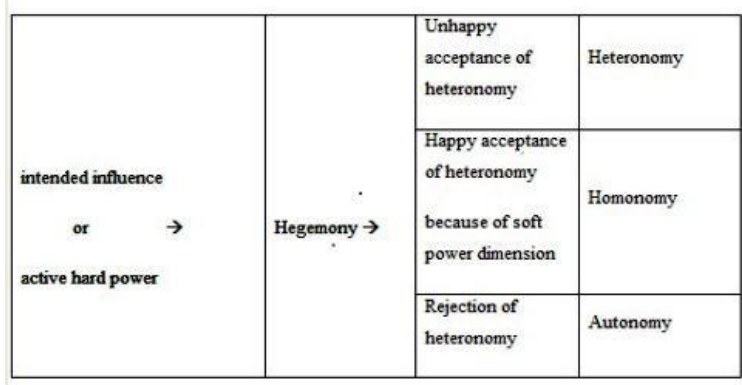

Sources: Chitty 2017a; Chitty 2017b

An overarching social construction, the international system, one that maybe characterized as a weak world confederacy with republican characteristics has emerged (Chitty 2017a). It has the republican characteristics of mixed government and the pursuit of Beauty in the form of commitment to enhance human security in the widest sense. "As stated in paragraph 143 of the 2005 World Summit Outcome (A/RES/60/1), entitled 'Human Security', the Heads of State and Government stressed 'the right of all people to live in freedom and dignity, free from poverty and despair', and recognized that 'all individuals, in particular vulnerable people, are entitled to freedom from fear and freedom from want, with an equal opportunity to enjoy all their rights and fully develop their human potential'. Human security aims at ensuring the survival, livelihood and dignity of people in response to current and emerging threats - threats that are widespread and cross cutting. Such threats are not limited to those living in absolute poverty or conflict". Human security aims at ensuring the survival, livelihood and dignity of people in response to current and emerging threats - threats that are widespread and cross cutting. Such threats are not limited to those living in absolute poverty or conflict" (United Nations Trust Fund for Human Security).

The incentive of achieving Beauty in the international system draws on norms and values in constructing regimes that regulate issue areas, such as the issue areas of agriculture, health, telecommunications or trade, to name a few. Krasner (1983) defines international regimes as "principles, norms, rules, and decision-making procedures around which actor expectations converge in a given issue area".

Technologies have arisen historically from a mind-body thought-action process in accomplishing tasks that could not be accomplished by body or mind alone. For Hall these are extensions and when these are reified he calls the process 'extension transference'. "Once people began evolving their extensions, particularly language, tools, and institutions, they got caught in the web of 'extension transference', and as a consequence, they err in judgment and become alienated from and incapable of controlling the monsters they have created" (Hall 1976). The technological environment of today is characterized by rapid introduction of new technologies and layer-upon-layer of extension transference; the generation of an increasingly digitized cyber sphere (the internet) that captures larger and larger swaths of media sphere (internet plus media) and info sphere (media sphere plus human mind and symbolic reality) (Ronfeldt \& Arqilla 2007); convergence of biological technologies (such as those based on cognitive and genome sciences) and electronic technologies (such as informatics, telematics and robotics). But without further progression towards bionic forms, human beings and human society may be characterized even today as quasi cyborgs, being irrevocably dependent today on digital extensions and having the propensity also for being extensions for the digital world - as witnessed in data storage in DNA by "translating the 1s and 0s of binary digital files into long strings of the four different nucleotides, or bases, that make up DNA strands and write out the genetic code" (Rosenblum 2016). This latter signals a new level of bio-informatic convergence.

Technological convergence has unfolded within the current uneven global societal convergence and evolution of rules and rule that emerge through the interplay of propensities for hierarchy, hegemony and heteronomy, propensities identified in Onuf's constructivism (Onuf 2014). It has afforded new venues for virtual social interaction and influence, both hard and soft power based, for construction of hierarchy, propagation of hegemony and institution of heteronomy, with varied responses of autonomy,from the extreme case of agents of commination to those who exercise mild forms of resistance, as well ascases where individuals construct experiences of homonomy. "Technologies have built-in affordances and so when technologies such as social media are used this is done purposively to benefit from their affordances.... once technologies are in place, from discrete intelligent software artefacts to the totality of socio- technological plexuses (cyber sphere, media sphere and info sphere) of Ronfeldt and Arqilla (2007). In the info sphere (the 
technological matrix of the world confederacy) there is also the merging of mind and technology even if the same technology hosts warring expressions of mind - from humanistic republicanism ... to commination" (Chitty 2017a, 2017b).

Human and machine intelligence and kinetics continue to converge within and with aworld confederacy that may be characterized as a growing 'cyber organization' - or system composed of human and social subsystems as well as other subsystems of human constructs ideological and technological. New theatres of culture and conflict and marketplaces for constructs and products also host virtual agents of organizations and individuals. Broadly these falls under the sway of Lasswellian symbolic, military and mercantile elites who control flows of symbols, weapons, and goods and services respectively (Lasswell 1963). The technologies of these elites have already converged electronically (Chitty 1992). Roboticization begins with sophisticated somatic extensions and increasingly is invested with elements of mind. Socially they begin by reinforcing existing orders of heteronomy, hierarchy and hegemony. Looking into the future, techno-social transformation may be projected to range between (1) a point where human mind (in its collective social expression as the world confederacy) is at the apex of the power hierarchy and (2) another where technology (in the wake of the singularity ${ }^{4}$ ) - that is no longer supported or ruled by human intelligence external to it - is at the apex. Inbetween there may be a range of Whole Brain Emulations (Ems) as described in Robin Hanson's (2016) The Age of Em: Work, Love and Life when Robots Rule the Earth. ${ }^{5}$ Currently the international system is

4 "Futurists like Vernor Vinge and Ray Kurzweil have argued that the world is rapidly approaching a tipping point, where the accelerating pace of smarter and smarter machines will soon outrun all human capabilities. They call this tipping point the singularity, because they believe it is impossible to predict how the human future might unfold after this point. Once these machines exist, Kurzweil and Vinge claim, they'll possess a superhuman intelligence that is so incomprehensible to us that we cannot even rationally guess how our life experiences would be altered" (Allen 2011).

5 Hanson, brings a formidable array of knowledge and research skills variously from physics, philosophy of science, social science served by converging informatics, telematics and robotic subsystems in the IoE. Interaction, including unwanted interaction, between mercantile, military, governance, knowledge and other systems takes place - with outlaw actors violating institutional borders by technological means.

The weak world confederacy has inter alia political subsystems, military subsystems, economic subsystems and cultural subsystems, as well as the digitized cybersphere, that increasingly incorporate crucial aspects of these subsystems. Because of the peripherals that are linked through the cybersphere and the increasing tendency to incorporate $\mathrm{AI}$ as peripherals - as well as humans and other biological forms - through bionics, the world confederacy is already emerging as a macro cyberorganism or rather as a cyberorganization. As AI within the system is enhanced, heteronomy by the world confederacy and its political subsystems over AI may become increasingly difficult to sustain; solutions based on battling for human autonomy, subjection to heteronomy or of homonomy will emerge. Indeed, these are depicted in science fiction movies about AI.

Drawing on Emery's (1997) view, 'Beauty' in the world confederacy would refer to an ideal of optimal human security with an outcome of happiness for all. Onuf has used the term hegemony "abstractly to describe a form of rule that manifests itself in a great variety of social arrangements...[and] that professionalization fosters hegemonial rule" (Onuf 1997). Professionalization of international civil servants and diplomats (associated with international organizations) who share ideas with professional academic and journalistic communities, may have led to norms for international regimes that are supportive of the existing heteronomy, hierarchy and hegemony. There are substantive and procedural norms. The former "provide standards for drawing up specific behavioural prescriptions" namely the non-discrimination, liberalization, reciprocity and safeguard norms. And the latter "provide guidelines regarding how states should design and use decision-making mechanisms" (Finlayson \& Zacher 1983). Hegemony, heteronomy and hierarchy become more acceptable, even exerting soft power, when invested with commissives of humanism. Today, the weak world confederacy and its state and substate members are in the foreground of power,

and artificial intelligence to the consideration of future AI scenarios. 
exercising heteronomy over technology through international regimes and national legislation. Even subscription to orientations of technological determinism by some states is a political decision and therefore fundamentally politically deterministic. It is when technological determinism can no longer be a political decision, when it has become an effect of autonomous technological construction (i.e. autonomous material and social construction by technology) that heteronomy over people, states and the world confederacy would have passed on to technology.

\section{Scenarios}

There are various future scenarios, from one where mind external to corporal being is subject to biological heteronomy (man rules machine) to one where the reverse is true (machine rules man). de Garis refers to supporters of universal expansion of artilects (more intelligent than humans), as cosmists; and those who oppose the growth of artilects he calls terrans. His third category are cyborgians, those who choose to merge in posthuman ways, perhaps at times individually homonomous ways, with intelligent machines - including through voluntary mind uploads into computers (de Garis 2005) ${ }^{6}$. There also are nightmarish scenarios such as those depicted in the Matrix trilogy. Matrix is about an AI-human system that comes into being after humans have been relegated to energy fodder by artilects. There appear to be vestigial humanist traits in the artilects who afford their human battery chickens a simulcrum of fin-de-siècle $20^{\text {th }}$ Century social life (Chitty 2008). It could also be argued that the AI in Matrix were following Asimov's 'three laws'. Super-intelligent computers are meant to be programmed according to Asimov's clearly humanistic laws: A robot may not injure a human being or, through inaction, allow a human being to come to harm; A

6 There already are social robots, one being "Bina48, a social robot considered to be one of the most advanced of her kind in the world. She runs on a type of software called a character engine, which allows her to interactwith humans at an unprecedented level. It may even allow her to evolve. Bina48 is based on a real human named Bina Rothblatt, who underwent over 80 hours of interviews to document her life experiences and memories. That information was then coded into Bina48, who uses Rothblatt's experiences, as well as she claims her own creative thoughts, to engage" (Ling, 2016). robot must obey the orders given it by human beings except where such orders would conflict with the First Law; A robot must protect its own existence as long as such protection does not conflict with the First or Second Laws (Asimov 2004). Even if the denizens of the Matrix, are variously happy or sad with their lots, the condition here cannot be described as homonomous. Their umwelten (world of one's own making) are not of their own making (Kull 2010). Apart for the awakened insurgents, the rest of humanity is oblivious to the power relations in the Matrix. They have not individually and voluntarily come to a homonomous relationship with the system. In our own world, powerful institutions may propagate messages that seek to encourage homonomy in members. However, homonomy should be a sui generis psychological construction of individuals.

The problem of challenges to human heteronomy over technology by artilects is examined repeatedly in science fiction movies. In the opening sequence of 2001: A space odyssey a black hyper-technological monolith appears in the African veldt millions of years ago; it influences the development of simple technological skills in primates who are on the cusp of being human. A similar monolith is found on the moon in 2001, signaling to Europa, the Galilean moon of Jupiter. David Bowman, the protagonist, belongs to a crew that is sent to Europa, in a spaceship driven by HAL 9000, (a heuristically programmed algorithmic computer) to investigate a monolith that had been emanating signals. HAL 9000 seemed to have made an autonomous decision in '2001: A space odyssey' by killing members of the crew who had wanted to abort the mission. He seemed to have broken Asimov's first law. It is explained in '2010: The year we made contact'that HAL 9000 had been especially programmed to place the mission first. HAL 9000 continued to be subject to heteronomy of man, but not so the super-intelligence behind the monoliths. In '2010: The year we made contact' we learn that through interaction with the monolith, Bowman had his mind uploaded into an AI whose materiality was of a quantum nature. 7 We have two levels of AI in the duology: A space odyssey' and '2010: The year we made contact' - AI that is subject to human

7 This reading is confirmed by the lead authorrecalling that he asked Sir Arthur C. Clarke, in Colombo in 1981, what Clarke thought of the idea of a computer that had only quantum materiality. Clarke responded that he was just then writing about this type of computer in the manuscript for "2010". 
heteronomy and AI that exercises heteronomy over humans and can host human mind emulations.

The following account summarizes Hanson's (2016) prognostications about an economy of emulated brains (Ems) that work for a living in virtual worlds or by inhabiting robots in the human world (Hanson 2016). Hanson predicts the creation of interactive artificial computing devices that can mimic an individual's brain signal patterns (to a level of perhaps 50\% efficiency) through a process he calls emulation. They are not examples of human-level AI; Hanson expresses the view that there would need to be several doublings of the Em economy before $\mathrm{AI}$ emerges and that when it does it will probably not be in one location. These lesser-minded Ems (lowergrade versions of their human originals) will form a labor force. Computational receptacles of Ems will be in dense controlled conditions in modular temporary buildings. Ems will have the capacity for violence, so they will be placated by highly desirable leisure time virtual realities. They will have virtual brains, bodies and offices. They will be organized into clans (functional groups) and teams (ascriptive but with informational diversity) within firms. Ems are predicted to be self-governed by Ems with optimal personality types, who willemploy decision/predictive/virtualmarkets to determine views on future events (Hanson 2016).In this possible world described by Hanson, humans will no longer work for money and will not be employed, but would reap benefits from the Em world. Is there then an assumption that Ems will at least initially be owned by humans, somewhat like shares that bring in dividends? If there are Ems of different capacity, a political economic approach might suggest that there will be a hierarchy of ownership with the cheaper ems (equivalent of bicycles in the transport arena) being owned by the majority at the base of the pyramid and the expensive Van Neumann machines (equivalent of Boeing 747s or ocean liners) being owned and controlled by the powerful and wealthy few at the top.

Hanson has not discussed the potential shape of world politics in an Em world but believes "an em world coordinates more often to deal well with the largest global threats or opportunities" (Hanson 2016). He predicts stronger global governance in association with the Em world but does not elaborate. Certainly, the contemporary international system does not cooperate evenly or adequately around all issue areas - and we have only to visit the difficulties that arise in cooperating on nuclear security. Security is very much a concern of governance and there needs to be a structure for governance that facilitates the ensuring of security for a system and its parts against external or internal threats to system stability.Asimov's first law is about protecting human beings rather than society or the international system. His second law reinforces the heteronomy of humans over computers. The third law is about self-preservation of AI, provided the first two laws are not compromised. The problem of self-preservation versus social preservation needs to be carefully addressed. An AI may conclude, even under Asimov's laws, that it is better for an international system to take a form of the $\mathrm{AI}^{\prime} \mathrm{s}$ prescription (that results in greater efficiency and system stability for instance) rather than a form preferred by humanity as expressed by its international institutions. Or its futurity calculus may be that the following would be unethical: [T]he happiness of present and proximate generations would be bought with the unhappiness or even non-existence of later ones" (Jonas, 1984, pp. 4, 5, 11)

\section{AI and state, regional and global governance}

Whenever a new challenge appears on the horizon, the world confederacy or subystemic elements such as states, international agencies and institutions, begin to address it from relevant policy perspectives. The regulation of emerging AI is no different. The U.S. National Science and Technology Council in association with the Executive Office of the President has published a report entitled Preparing for the future of artificial intelligence that is important in that it is an attempt by the leader of the hegemonic coalition of the West and the major technological innovator, to develop norms for its AI sector (Executive Office of the President 2016). This report, a public document, is quite comprehensive in scope, including economic, governance, research, and security issues;itoffers 23 recommendations. Another US initiative in this area is an examination of the outlook for Asia. A report entitled Asia's AI agenda: How Asia is speeding up global artificial intelligence adoption is however mostly focused on the business sector (MIT Technology Review 2016). The UK Government Office of Science sets out a plan of action: "The right form of governance for artificial intelligence, and indeed for the use of digital data more widely, is not self-evident. It is important to consider forms of data governance that cover all elements of the increasingly complex space, from responsibly generating data from people's behaviour to remaining accountable for autonomous software agents. Additionally, any 
approach adopted must be flexible, able to adapt to new uses and more advanced forms of artificial intelligence. There are many models that can be considered. But the important task is to set out what needs to be done before considering how it is to be achieved" (Government Office of Sciences 2015). Having briefly recounted US and UK initiatives, this section will mostly discuss the "European Parliament resolution seeking the introduction of legislation and an ethics code concerning artificial intelligence and robotics" whereby the European Parliament's Legal Affairs Committee on 12 January 2016 announced it would introduce 1) new legislation concerning AI and robotics; and 2) an ethics code of conduct to be voluntarily applicable to designers and developers and that the anticipated draft proposals will be based on parts of the European Parliament's Committee on Legal Affair's Draft Report (2015/2103INL) of 31 May 2016 drafted by MEP Mady Delvaux.

The Draft Report Suggestions 8 begin by addressing definitional, registration, civil liability, interoperability/access, intellectual property and industry disclosure issues. The proposals then go on to consider ethics and licensing issues. Specifically it is suggested, that in seeking to define the term "smart robots," consideration must be given to the following (Draft Report, 2016): “The capacity to acquire autonomy through sensors and/or by exchanging data with its environment (inter-connectivity) and the analysis of those data; The capacity to learn through experience and interaction; The form of the robot's physical support; The capacity to adapt its behaviours and actions to its environment" (Draft Report, 2016). A 'smart robot' is therefore not required to be fully sentient, it need only be able to interact with its environment, analyze data, learn new information and/or skills and adapt its behaviours through its experiences. A Unionwide system of registration of advanced robots, to be presided over by an EU Agency for Robotics and Artificial Intelligence, is suggested (Draft Report, 2016). It is suggested that in cases other than those involving damage to property, legal remedies should not limit the damage or forms of compensation that may be recovered solely on the basis that the damage was caused by a nonhuman agent (Draft Report, 2016). It is recommended that a rule of strict liability should

$8^{\prime}$ Draft Report Suggestions' are in the 'Annex to the Motion for a Resolution: Detailed Recommendations as to the Content of the Proposal Requested,' pp. 13-20 of the Draft Report. apply to damage caused by 'smart robots' (Draft Report, 2016). Strict liability involves the imposition of liability without the need for establishing the existence of negligence or tortious intent. All that would be needed would be to prove the existence of a "causal link between the harmful behaviour of the robot and the damage suffered by the injured party" (Draft Report, 2016). An obligatory insurance scheme is proposed with the producer being obliged to take out insurance for its autonomous robots (Draft Report, 2016). It is suggested the scheme be accompanied by a supplementary fund to cover any uninsured cases(Draft Report, 2016). The Draft Report Suggestions provide that it is important to ensure the interoperability of autonomous robots that interact with each other over a network(Draft Report, 2016). The source code for such a network of robots should also be accessible for following up smart robots' accidents and any resulting damage (Draft Report, 2016).

Transparency from users of smart robots would require institutions to disclose the number of smart robots they use (Draft Report, 2016), the savings the smart robots afford them and the proportion of revenue resulting from robots and AI (Draft Report, 2016). "Undertakings should be obliged to disclose: the number of 'smart robots' they use -the savings made in social security contributions through the use of robotics in place of human personnel - an evaluation of the amount and proportion of the revenue of the undertaking that results from the use of robotics and artificial intelligence" (Draft Report, 2016). A charter on robotics is contained in the Draft Report Suggestions for providing principles to guide and supplement the: 1) Commission in proposing robotics legislation; and 2) design and development phase of robotics production. The principles are supposed to follow a hierarchy of values that would be sophisticated enough to be applied with success on a case by case basis. It is hoped that at the research and development level, the hierarchy of ethical principles/values will set ethical standards and inform processes that will resolve ethical dilemmas (Draft Report, 2016).

The Code of Ethical Conduct for Robotics and Engineers is voluntary and lays out principles of ethics drawing on human rights principles that echo the Universal Declaration of Human Rights (United Nations): rights to life and safety (Article 3 ), and privacy (Article 12), the underlying right to human dignity (Article 1); Asimov's Laws (Asimov 2004); and the 'first do no harm' promise of the Hippocratic oath (National Institute of Health).Specifically, the principles are: 1) 
beneficence (acting in the best interest of humans), 2) non-maleficence ('first do no harm' and do not harm a human), 3) autonomy (humans are to be able to make un-coerced decisions concerning the manner in which they interact with robots; 4) justice - the benefits arising from the use of robots must be distributed fairly and robot use for social welfare in particular should be affordable (Draft Report, 2016). The 'fundamental rights' identified in the ethical conduct proposals are comprised of the following:"1) The right to human dignity;2) The precautionary principle (taking due precautions proportional to the level of protection;3) Inclusiveness - the right of access to information by all stakeholders; 4 ) Accountability -for the social, environmental and human health impacts that robotics may impose on present and future generations;5) Human safety;6) The reversibility of most recent sequence of robots programming;7) Privacy - people are not to be personally identifiable; and8) Maximising benefit and minimising harm (harm to research participants should not exceed that encountered in day-to-day life)". The draft code for research ethics committees requires that members be accountable, competent and independent, and show transparency. In broad termssuch a committee must ensure independent, competent and timely reviews of research with a view to protecting research participant and stakeholder interests, to assessproposals' scientific merit and to offer recommendations (Draft Report, 2016).

The European Parliament's Draft Report Suggestions seek to consider all the implications of AI and are intended to address a new industrial revolution 'which is likely to leave no stratum of society untouched' (Draft Report, 2016). The European Parliament would have considered in its proposals the advice provided to the JURI Committee in 2014 in Bertolini and Palmerini's paper 'Regulating Robotics: A Challenge for Europe' (based on work prepared under the RoboLaw Project). Broadly speaking, the advice included the following: 1) Concurring on a comprehensive definition of robots would not be possible, robots being variegated and therefore needing to be addressed on a case-bycase basis; 2) values and fundamental rights must be protected as a priority (Bertolini and Palmerini, 2014). Applications need also to be considered separately on the bases of issues raised, and the ways in which fundamental rights may be upheld or diminished. "If this analysis is conducted at a sufficiently early stage regulation could contribute to determine how such devices ought to be conceived for rights to be protected (e.g.: privacy by design)" (Bertolini and Palmerini, 2014).Whilst it is important to adopt a flexible and case-by-case approach to an unfolding situation such as the regulation of robotics and AI, the nature of these technologies calls for strict measures to be taken to prevent increasingly sophisticated and rapidly evolving AI from overpowering humanity due to a paucity of restraints on its ability to infiltrate every facet of modern human existence. If we are concerned that AI could end up at the apex of a world confederacy and enforce values that are antagonistic to humanity, or that it could precipitate anarchy by rejecting the authority of a human-led world system, then it is necessary at this early stage to strictly manage the impact of $\mathrm{AI}$, at least in the foreseeable future, through actions such as these:1) Limit the connectivity and proliferation of the IoT;2) Ensure that AI does not attain legal personhood prematurely or unnecessarily ${ }^{9}$;3) Ensure that AI is always programmed to submit to human authority and that it always can be disabled by a human; and4) Adopt international ethical standards for the regulation and research of robotics and AI that can be applied consistently throughout the world.

The Draft Report Suggestions are commendable in their balancing of the need to allow laws to develop alongside technology whilst impeding AI's ability to develop beyond human heteronomy. For example, the proposals provide adequate guidelines for attempting to achieve the first, third and fourth objectives. As for the second objective, (the attainment of legal personhood), the Draft Report discusses the problematic nature of sophisticated robots, that lack legal personhood, thereby suggesting that legal personhood should be explored in the future. Even so, the Draft Report Suggestions themselves do not suggest legal personhood and merely indicate a strict liability model to be implemented in the foreseeable future with respect to damage caused by 'smart robots' (Draft Report, 2016). The short-term approach of the Draft Report Suggestions is therefore consistent with the objective of approaching legal personhood for robots cautiously and on a caseby-case basis. The suggested strict liability approach for all damage caused by smart robots could serve to keep the onus of responsibility

9 There have been suggestions that algorithms may one day be recognized as legal persons (Harari 2015, 323). 
squarely on the shoulders of human owners and producers of robots, thus incentivising them to keep tight controls on the quality and conduct of their robots. It is intended that strict management of robots and their conduct should have the effect of limiting AI's ability to exert undesirable influence, when coupled with a strong culture of protecting fundamental human rights in the field of robotics.

Finally, the Draft Report Suggestions do offer a starting point for defining robots but have not provided a conclusive definition and thus leave room for decision makers to deal with each robot type on a case- by-case basis. Indeed, a large proportion of the suggestions remains dedicated to the topics of ethical standards and fundamental rights, as opposed to robot and AI definitional issues or confining legal procedures. Whereas the suggestions do recommend practical steps for putting measures in place to effectively control AI at this early stage, they have placed a great deal of emphasis on the protection of key human values. The suggestions have taken positive steps towards achieving their intended purpose which was to mitigate the risks posed by $\mathrm{AI}^{\prime}$ 's 'increasing interaction with humans in very diverse fields' (Draft Report, 2016) by 'ensuring that a set of core fundamental values is translated into every stage of contact between robots, AI and humans. In this process, special emphasis [was to be] given to human safety, privacy, integrity, dignity and autonomy'(Draft Report, 2016). Human safety, privacy, integrity, dignity and autonomy are addressed throughout the suggestions, and the successful protection of these fundamental values may have as a by-product the effect of sufficiently limiting the capacity of AI to become self-serving and detrimental to humanity - at least in the near future.

We see in this process, professionals engaging in a normativization that fits in with the search for Beauty, for humanist outcomes. Deliberations at national, regional and international level will give rise to a formalor informal AI international regime in the future.Formal international regimes "are legislated by international organizations...and monitored by international bureaucracies" while informal ones "are created and maintained by convergence or consensus in objectives among participants, enforced by mutual self-interest..." (Puchala and Hopkins 1983, 65). AI has grown to be an issue area of interest for UN agencies. For instance, UNICR, the United Nations Interregional Crime and Justice Research Institute recognizes that concerns about potential criminal use of AI "are amplified where an AI system is capable of evolving beyond its original program to act in a manner that may be considered more efficient. In order to strike a balance between the technological advances in AI and robotics and the need to appropriately consider and address the full spectrum of potential security implications of these technologies, UNICRI seeks to [c]apture perceptions and facilitate a common understanding of the concepts of AI and robotics; [c]ultivate a community of stakeholders in the field of AI and robotics; [e]nsure that the risks posed by present and potential future security implications for AI and robotics are appropriately mitigated" (UNICR). Norms and soft law negotiated by member states in the world confederacy encourages states to conform and conform happily if the construction has a character of homonomy. Some states may strive for greater autonomy from the world confederacy and others may seek to strengthen the confederacy. Some actors may act as outlaws in the global community. "The global polity, tighter here and looser there, is based on internationally accepted rules and states and non-state actors adhering to the consensual rulemaking and rule framework - as well as outlaws and recusants and polities that have not been accredited by the system" (Chitty 2017a). AI may give one state and advantage over others but may present grave dangers as well; thus, it does need the development of an international regime.

Artilecture, embedded with AI invested with deep learning capability, will be able to draw on the range of human norms, values, beliefs and behavior, as well as on Big Data that will offer 'it' greater predictive capability than we have ever known. There is an emerging notion that "consciousness seems to depend on how different parts of the brain speak to each other, in specific ways" (Seth 2016). Could we conceive that in an artilecture that incorporates a constellation of AIs, the AIs could act like different parts of a brain and develop consciousness? Consciousness is seen as a product of 'emergence'. "The basic idea of emergence is that qualitative novelty can appear when parts which themselves lack that quality are organized in a certain way, like unsolid molecules becoming a solid rock" (Wendt 2015). Arguably consciousness needs a system but under what conditions does consciousness emerge from system complexity? Can advanced consciousness be hosted in quantum computers? At the same time, it is interesting to note that the cyberorganization of the world confederacy, despite the constant chatter and the seeming prescience of Teilhard de Chardin et al (1959), has not given rise, as an emergence, to a global 
consciousness - or even to the consciousness of a lesser political system such as a nation state. Or if it has, it is of a different order to human consciousness. Esprit de corps of nationalness has great currency across the globe. But the international system has little in the way of esprit de corps. Despite this there is the world confederacy with its humanist intent.Wendt (2015) argues "that where there is no consciousness there is no intentionality". Nonetheless the collectively bargained intent of the world confederacy does not appear to invest it with a consciousnessof the same ilk asthat which we experience in ourselves.

In shaping the pre-singularity future, with the intent of shaping the singularity for the benefit of future generations, the world confederacy needs to ensure that humanist norms govern the (1) issue area of AI; (2) national AI law; (3) AI research and development; (4) A1 ownership and use. Further AI should be associated with other actors' cyborganization of the world confederation - in a condition of homonomy. On the other hand, Harari $(2015,311)$ notes that despite "an immense advance in computer intelligence... there has been exactly zero advance in computer consciousness" and warns that "[h]umans are in danger of losing their value, because intelligence is decoupling from consciousness" (Harari 2015, 327). He further sees liberal humanism being displaced by technohumanism driven by consciousness-free intelligence (Harari 2015, 359). There will be slave computers and robots and master AIs, but the enslaving of people by $\mathrm{AI}$ is a heteronomy that will be difficult to countenance. It is to preempt the possibility of humans degrading AI that AI "might simply exterminate mankind" (Harari $2015,327)$. If there could be participation of AI in a humanist governance and economy, that may be a positive thing. It is important for regime constructing institutions, that will emerge in the issue area ofAI, to construct humanistic norms at the systemic level - that can then be translated to policy and law within states - that will regulate the human cultivation of AI by industryeducation coalitions.

\section{Conclusion}

We have addressed above the rapid evolution of AI in a world where the line between human and technology is becoming increasingly blurred. Indeed, as we increasingly use all technologies as extensions of ourselves, our ability to measure and define the magnitude of their influence over the world around us is hindered. AI's interaction with humanity both at an individual level and at an international political level is considered from an international relations perspective. AI can be an add-on to human intelligence on an individual level, and at more extended levels through social media and the IoE. It follows that AI is an emerging influencer of politics, society and anything within the purview of the IoE. An important question is whether 1) a sentient and sophisticated AI will eventually become the shaper of the world confederacy; 2) human society will continue to shape the world confederacy ensuring that AI follow humanist norms); or 3) human society and AI will merge variously at the apex of a world confederacy with one not being distinguishable from the other. We have raised the additional question of whether submission by human, AI or human/ AI hybrids to whichever entity or system is at the apex of the world system will be willing, unwilling or not forthcoming at all.

We have herein examined conceptions of relationships between $\mathrm{AI}$ and society through the lens of constructivism drawing on Onuf's three rules of functional grounds for world politics, viz. hegemony, hierarchy and heteronomy (Onuf 2014) and introducing the notion of homonomy (Chitty 2017a). It described a humanism and human security oriented weak world confederacy that was already a cyberorganization. The response of a positive self-surrender, based on the right balance of reciprocal constraints resulting in a happy acceptance of the relationship, in homonomy, has been proposed between humans and technology, with the incentive of achieving Beauty in the international system, Beauty being an ideal of optimal human security and happiness. While challenges to heteronomy over society by artilects, is examined in science fiction, there is the notion that super-intelligent computers can be programmed according to Asimovs' three human-oriented laws. There are also nightmarish narratives of outlaw artilects seeking or gaining heteronomy over mankind. We need to strive to ensure that AI's, as they develop a psychology, can build a condition of homonomy for themselves within a larger humanistic system. Nation states, such as the United States, and international organizations such as the European Union and United Nations, have begun to examine the implications of AI and propose norms and laws. It is important that the emerging artilectural regime should have the objective of facilitating cyberorganizational homonomy within a humanistic culture. Ensuring that the algorithms of computers, nations and the world confederacy resonate in terms of the values of humanism may help, such that a future world of posthuman hybridities will be one that is 
characterized by soft power and a profusion of homonomy rather than hard power and heteronomy. And content and communication will play a role in the facilitation of communities of homonomous individuals who are content with their situation.A soft power perspective aimed at outcomes of Beauty for society and homonomy in relationships with a system (one having a strong AI character) may, at least for a while, shape social transformation that incorporates AI.

Professor Naren Chitty A.M. is the Inaugural Director of the Soft Power Analysis and Resource Centre (SPARC) and Foundation Chair in International Communication, MMCCS, Faculty of Arts at Macquarie University. He has a PhD in International Relations from the School of International Service of the American University, Washington D.C. He has had a longstanding interest in issues related to Artificial Intelligence and was a member of the group that set up the Arthur C. Clarke Foundation of the U.S. and took part in the preliminary discussions that led to the founding of the International Space University. He has published an article on "PR of Artilects". His current interest is in the notion of homonomy in power relations.

Sabina Dias LLM (Macquarie) BA / LLB (UNSW) is an Australian lawyer. Her research interests include international law, jurisprudence, media law and robot law. She was admitted as a lawyer of the Supreme Court of New South Wales in 2011. Sabina has worked in the areas of commercial litigation, building \& construction, criminal, bankruptcy, migration and administrative law and has experience in both the private and public sectors.

\section{References}

Allen, P (2011). 'The singularity is near'. MIT Technology Review. October 12, 2011. Viewed 8 December 2016 https://www.technologyreview.com/s/42 5733/paul-allen-the-singularity-isnt-near/

Angyal, A (1969). 'A logic of systems'. In Emery, F. Systems thinking. Harmonsworth: Penguin. pp. 17-29.

Asimov, I. (2004). I, Robot. New York: Bantam Books.

Berkowitz, A. (2016).'Is Your Nervous System a Democracy or a Dictatorship?'Scientific American viewed 8 December 2016 https://www.scientificamerican.com/artic le/is-your-nervous-system-a-democracyor-adictatorship/?WT.mc_id=SA_FB_MB_NE WS von Bertalanffy, L. (1972). 'The History and Status of General Systems Theory'.Trends in General System Theory, Ed. Klir, George, Wiley-Interscience, New York.

Bertolini, A. and Palmerini, E. (2014). Legal and Parliamentary Affairs - Workshop on Upcoming Issues of EU Law. European Parliament Directorate-General for Internal Policies, pp.167-202.

Chitty, N. (1992).'Development is Communication: Self-reliance, selfdevelopment, and empowerment'. Telematics and Informatics. 9,1. $21-42$.

Chitty, N. (2008). 'PR and artilects'. Journal of Public Relations and Advertising, Vol.1, No. 2.

Chitty, N. (2017a). 'Soft power, civic virtue and world politics'. In Routledge Handbook on Soft Power, Eds. Chitty, Naren, Ji Li, Gary Rawnsley \& Craig Hayden. Routledge, Oxfordshire

Chitty, N. (2017b). 'Conclusion'. In Routledge Handbook on Soft Power, Eds. Chitty, Naren, Ji Li, Gary Rawnsley \& Craig Hayden. Routledge, Oxfordshire

CISCO. 'Internet ofEverything', viewed 7 December 2016 <http://ioeassessment.cisco.com/learn/io e-faq $>$

Self-replicating machines named after the physicist/computer scientist John Von Neumann.

de Garis, H. (2005). The artilect war: Cosmist Vs. Terrans: A bitter Controversy concerning whether humanity should build godlike massively intelligent machines. Etc Publications

Easton, D. (1965). A Framework for Political Analysis. Englewood Cliffs, N. J.: PrenticeHall, Inc.

Emery F. (1977). Futures we are in. Leiden: Martinus Nijhof.

English Oxford Living Dictionaries Viewed 7 December 2016 https://en.oxforddictionaries.com/definiti on/ideology

Epictetus (1925). The Discourses as reported by Arrian; The manual ; and, the fragments. Cambridge, Mass: Harvard University Press

European Parliament Press Service (Directorate for Media), (2017). 'Robots: Legal Affairs Committee calls for EU-wide rules' 
(20170110IPR57613). European Parliament Press Service, pp.1-2.

European Parliament Committee on Legal Affairs, (2016). "Draft Report 2015/2103(INL)". pp.1-22

Executive Office of the President (2016). 'Preparing for the future of artificial intelligence'

Finlayson, J. \&M. Zacher (1983). 'The GATT and regulation of trade barriers'. In International regimes, Ed. S. Krasner. New York: Cornell University Press.

Government Office for Science. 2015. 'Artificial Intelligence: Opportunities and implications for the future of decisionmaking'. Viewed 8 December 2016 https://www.gov.uk/government/upload s/system/uploads/attachment_data/file/ 566075/gs-16-19-artificial-intelligence-aireport.pdf

Hall, E. (1976). Beyond Culture, New York: Doubleday.

Harari, Y. (2015). Homo Deus: A Brief History of Tomorrow. London: Harvill Secker.

Hardin, R. (1982). Collective action. Baltimore: Johns Hopkins University Press.

Hanson, R. (2016). The Age of Em: Work, Love and Life when Robots Rule the Earth. Oxford: Oxford University Press

Jonas, H. (1984) The Imperative of Responsibility. Chicago: The University of Chicago Press

Krasner, S (1983). International regimes, New York: Cornell University Press.

Kull, Kalevi (2010). "Umwelt". In Cobley, Paul. The Routledge Companion to Semiotics. London: Routledge. pp. 348-349

Lasswell, H. (1963) [1935], World politics and personal insecurity, New York: The Free Press.

Ling, L. (2016). 'Is AI the next phase of human evolution. Seeker. 14 July 2016. Viewed 8 December 2016

http://www.seeker.com/is-artificialintelligence-the-next-phase-of-humanevolution1921769603.html?utm_campaign=socialflo w\&utm_source=facebook\&utm_medium= dnewssocial

Dobbin, R. (2008), Discourses and Selected Writings. Penguin Classics
National Institute of Health. 'Greek Medicine'. Viewed $25 \quad$ January 2017 https://www.nlm.nih.gov/hmd/greek/gr eek_oath.html

Merriam-Webster Dictionary, Viewed 7 December 2016 https://www.merriamwebster.com/dictionary/technology

MIT Technology Review. 2016. Asia's AI agenda: How Asia is speeding up global artificial intelligence adoption. Boston, MIT.

Morgan, J. (2014). 'A Simple Explanation of 'The Internet of Things', Forbes May 13. Viewed: http://www.forbes.com/sites/jacobmorga $\mathrm{n} / 2014 / 05 / 13 /$ simple-explanationinternet-things-that-anyone-canunderstand/\#6b8d18d66828

Nye, J. (2011). The future of soft power. New York: Public Affairs.

Onuf, N. (1997. 'Hegemony's Hegemony in IPE'. In Constituting International Political Economy. Eds. K. Burch\&R. Denemark. Boulder, Colo: Lynne Rienner Publishers, pp. 91-92

Onuf, N. (2014). 'Rules and rule in international relations', Erik Castrén Institute of International

Law and Human Rights, University of Helsinki, viewed 13 January 2016, < www.helsinki.fi / eci/ Events/ Nicholas\%20Onuf_ Rule\%20and\%20Rules\%20\%204- 2- 14.pdf >

Puchala, D. \& R. Hopkins (1983). 'International regimes: Lessons from inductive analysis'. In International regimes, (ed) S. Krasner. New York: Cornell University Press.

RoboLaw (2014). 'Regulating Emerging Robotic Technologies in Europe: Robotics facing Law and Ethics', Viewed 25 January 2017, http://www.robolaw.eu/

Robolaw.eu. (2017). 'RoboLaw - Project Overview'. Viewed 28 January 2017, http://www.robolaw.eu/projectdetails.ht m\#RoboLaw\%20Overview

Ronfeldt D. \& J. Arquilla, J, (2007), ' The promise of noöpolitik' , First Monday, vol. 12 , no. 8, viewed

10 November 2015, < www.fi rstmonday.org/ ojs/ index.php/ fm/ article/ view/ 1971 >.

Rosenblum, A. (2016). 'Microsoft reports a big leap forward for DNA data storage'. MIT Technology Review. July 7, 2016, Viewed 8 December https://www.technologyreview.com/s/60 
1851/microsoft-reports-a-big-leap-forwardfor-dna-data-

storage/?utm_campaign=socialflow\&utm source $=$ facebook\&utm_medium $=$ post

Seth, A. (2016). 'The real problem'. Aeon. Viewed $8 \quad$ December 2016 https://aeon.co/essays/the-hard-problemof-consciousness-is-a-distraction-from-thereal-one

Teilhard de Chardin, P, J. Huxley \& B. Wall (1959). The phenomenon of man. New York: Harper.

United Nations. 'Universal Declaration of Human Rights'. Viewed 27 January 2017 http://www.un.org/en/universaldeclaration-human-rights/
UNICR. 'Robots and Artificial Intelligence'. Viewed 8 December 2016 http://www.unicri.it/special_topics/Robo tics_Artificial_Intelligence/

United Nations Trust Fund for Human Security, 'Human security for all', viewed 28 November 2016, http://www.un.org/humansecurity/about -human-security/human-security-all

Wendt, A. (2015). Quantum mind and social science: Unifying physical and social ontology, Cambridge: Cambridge University Press.

Wendt, A. (1999). Social theory of international politics, Cambridge: Cambridge University Press. 